5 A. C. Aisenberg and H. P. Morris, Nature, I9I (I96I) I3I4.

6 H. P. Morris, H. Sidransky, B. P. WAgner and H. M. Dyer, Cancer Research, 20 (I960) I 252.

7 V. R. POTter, Cancer Research, 2 I (I96I) I33I.

8 G. Gentry, P. A. Morse and V. R. Potter, Proc. Am. Assoc. Cancer Research, 3 (I962) $32 \mathrm{I}$.

9 C. Peraino and A. E. Harper, Anal. Chem., 33 (I96I) I863.

10 W. W. Umbreit and N. E. Tonhazy, J. Biol. Chem., IgI (I95I) 249.

11 M. E. Smith ANd D. M. Greenberg, J. Biol. Chem., 226 (1957) 3 I 7.

12 H. S. Strecker, J. Biol. Chem., 235 (Ig6o) 2045.

13 M. S. Dunn AND E. A. MurPhy, Cancer Research, I8 (I958) 569.

14 A. Meister, Biochemistry of the Amino Acids, Academic Press, Inc., New York, 1957, p. 290.

15 E. Roberts and D. G. Simonsen, in J. T. Edsall, Amino Acids, Proteins, and Cancer Biochemistry, Academic Press, Inc., New York, I960, p. I2I.

16 W. K. MAAs, Cold Spring Harbor Symposia Quant. Biol., 26 (1961) I83.

17 H. V. Ricken BerG, Cold Spring Harbor Symposia Quant. Biol., 26 (196I) 366.

Received April I6th, 1962

Biochim. Biophys. Acta, 62 (1962) 585-587

$\operatorname{SC} 2 \mathrm{II} 3$

\title{
On the conversion of sodium dimethyldithiocarbamate into its $\alpha$-aminobutyric acid derivative by microorganisms
}

Plant tissues have been shown to transform the fungicide sodium dimethyldithiocarbamate into two other fungitoxic products namely the $\beta$-glucoside ${ }^{1}$ and the alanine derivative $\left(\mathrm{CH}_{3}\right)_{2}: \mathrm{N} \cdot \mathrm{CS} \cdot \mathrm{S} \cdot \mathrm{CH}_{2} \cdot \mathrm{CHNH}_{2} \cdot \mathrm{COOH}$ (ref. 2 ).

It was deemed worthwhile to investigate whether microorganisms are also capable of performing these transformations. Sodium dimethyldithiocarbamate being an antimicrobial agent it seemed indicated to use dense cell suspensions instead of growing cultures. Of fresh commercial baker's yeast, Saccharomyces cerevisiae, $600 \mathrm{mg}$ were suspended in $20 \mathrm{ml}$ of $0.03 M$ phosphate buffer $(\mathrm{pH} 7.0$ ) containing I \% glucose, O.I \% ammonium carbonate and $20 \mathrm{mg}$ of sodium dimethyldithiocarbamate. The cell suspension was then incubated on a shaking machine at $24^{\circ}$. After $20 \mathrm{~h}$ a sample was added to an equal volume of $96 \%$ thanol and of the resulting supernatant $0.02 \mathrm{ml} / \mathrm{cm}$ were transferred to Whatman paper $3 \mathrm{MM}$ and chromatographed with propanol-water $(85: 15, v / v)$. The strip was then sprayed with a conidial suspension of Glomerella cingulata in glucose-mineral salts solution according to the technique of DEKHUIJZEN for the detection of fungitoxic spots ${ }^{3}$. After 2 days incubation three fungitoxic spots were seen on the strip, namely at $R_{F} 0.30, R_{F} 0.39$ and at $R_{F} 0.87$, the latter being the $R_{F}$ value shown by pure sodium dimethyldithiocarbamate ${ }^{3}$. If ammonium carbonate was not added, the spot at $R_{F} 0.30$ did not appear; if glucose was omitted neither of the new spots was seen, irrespective of the presence of the ammonium salt.

We succeeded in isolating and characterizing the compound with $R_{F} 0.30$ in the following way. $3 \mathrm{~kg}$ of baker's yeast were suspended in a solution of roog ammonium carbonate, roo g ammonium phosphate and Io g sodium dimethyldithiocarbamate in Ioo 1 of water. In the course of $15 \mathrm{~h} g 0 \mathrm{~g}$ of sodium dimethyldithiocarbamate and $2 \mathrm{~kg}$ of glucose were added to the aerated suspension, the temperature being kept between 20 and $25^{\circ}$.

After centrifugation the supernatant was concentrated in vacuo to I 1 . This concentrate was added to 41 of ethanol, the resulting heavy precipitate being discarded. The supernatant was treated with lead acetate followed by addition of sodium 
phosphate in order to remove the excess of lead acetate. The filtrate was concentrated again in vacuo to a syrup, which was then submitted to a counter-current distribution in butanol - ethanol - water $\left(5^{2}:\right.$ II $\left.: 37, v / v\right)$. The positive fractions, containing the compound with $R_{F} 0.30$, were pooled, concentrated and submitted to a countercurrent distribution in butanol - acetic acid - water $(4: I: 5, \mathrm{v} / \mathrm{v})$.

The positive fractions were concentrated in vacuo to a syrup which was subsequently dried in vacuo over solid $\mathrm{KOH}$. The residue was dissolved in $100 \mathrm{ml}$ of boiling water. In the course of the next $24 \mathrm{~h}$ the desired compound crystallized. After recrystallization from water $5 \mathrm{~g}$ of needle-shaped crystals were obtained. These were moderately soluble in cold water, but very soluble in acids or bases. The compound was optically active, developed a purple colour with ninhydrin and gave the following analysis: C, 35.19; H, 6.85; N, II.54; S, 26.4I. (Calcd. for $\mathrm{C}_{7} \mathrm{H}_{14} \mathrm{~N}_{2} \mathrm{O}_{2} \mathrm{~S}_{2} \cdot \mathrm{I}_{2} \mathrm{H}$ : C, 34.98; H, 6.7I; N, II.65; S, 26.68.)

The compound is rather stable to acid hydrolysis. $3 \mathrm{~h}$ boiling with $\mathrm{I} 2 \mathrm{~N} \mathrm{HCl}$ caused a hydrolysis of about 50\% and gave rise to two amino acids: homocystine and homoserine. From the above it seemed probable that the compound is $\gamma$-(dimethylthiocarbamoylthio)- $\alpha$-aminobutyric acid; presumably the L-form: $\left(\mathrm{CH}_{3}\right)_{2}: \mathrm{N} \cdot \mathrm{CS} \cdot \mathrm{S}$. $\left(\mathrm{CH}_{2}\right)_{2} \cdot \mathrm{CHNH}_{2} \cdot \mathrm{COOH}$.

Definite proof was obtained through the synthesis of the DL-form by Dr. Plujugers and Mr. Berg of this Institute. The isolated and synthetic materials gave identical $R_{F}$ values in different solvent systems and identical infrared spectra. Details of the synthesis will be published elsewhere.

The compound with $R_{F} 0.39$ which initially was present in the culture medium appeared to be unstable and was lost owing to decomposition during the purification of the aminobutyric acid derivative. Yet we have reason to believe that this compound is the corresponding $\alpha$-keto acid, $\left(\mathrm{CH}_{3}\right)_{2}: \mathrm{N} \cdot \mathrm{CS} \cdot \mathrm{S} \cdot\left(\mathrm{CH}_{2}\right)_{2} \cdot \mathrm{CO} \cdot \mathrm{COOH}$, because the proportion in which this unstable product and the aminobutyric acid derivative were formed appeared to depend on the amount of ammonium salt added.

Not only commercial baker's yeast but washed suspensions of Bacterium coli, Saccharomyces cerevisiae and Hansenula anomala, as well as mycelial pellets of Glomerella cingulata, Aspergillus niger and Cladosporium cucumerinum, proved to be able to transform dimethyldithiocarbamate into one or both fungitoxic compounds.

On the other hand the aminobutyric acid derivative is toxic to many microorganisms. Table I gives comparable values for growth-inhibitory concentrations of sodium dimethyldithiocarbamate and the $\mathrm{L}$-form of the aminobutyric acid derivative.

The action of the latter compound is antagonized by chelating agents in the same way as the action of dimethyldithiocarbamate itself ${ }^{4}$. This means that also in the case of the aminobutyric acid derivative a copper dimethyldithiocarbamate complex is the actual toxic agent; we must conclude therefore that under physiological conditions the aminobutyric acid derivative can be split and thus give rise to a copper complex of dimethyldithiocarbamate.

This brings us to the enzymic mechanism of synthesis and breakdown of the aminobutyric acid derivative. Although definite proof is still lacking we suggest that the dimethyldithiocarbamate is able to replace cysteine in its physiological coupling with homoserine thus giving rise to the formation of the aminobutyric acid derivative of dimethyldithiocarbamate instead of to cystathionine, the aminobutyric acid derivative of cysteine. The microbial conversion of cysteine into methionine by way 
of cystathionine is reversible and this may explain that also dimethyldithiocarbamate can be liberated again from its aminobutyric acid derivative, a reaction required for toxic action of this latter compound. We have in fact been able to detect dimethyldithiocarbamate after incubation of the aminobutyric acid derivative with pellets of $G$. cingulata under certain conditions.

\section{TABLE I}

GROWTH-INHIBITORY ACTION OF SODIUM DIMETHYLDITHIOCARBAMATE AND ITS $\alpha$-AMINOBUTYRIC ACID DERIVATIVE

\begin{tabular}{|c|c|c|}
\hline & \multicolumn{2}{|c|}{$\begin{array}{c}\text { Minimum concn. (parts/million) giving } \\
\text { complete grotth inhibition } \$\end{array}$} \\
\hline & $\begin{array}{l}\text { Sodium dimethyl- } \\
\text { dithiocarbamate }\end{array}$ & $\begin{array}{l}\boldsymbol{\alpha} \text {-A minobutyric } \\
\text { acid derivative }\end{array}$ \\
\hline Glomerella cingulata ${ }^{\star}$ & 0.2 & 2 \\
\hline Gloeosporium fructigenum * & 0.5 & 2 \\
\hline Botrytis allii ${ }^{\star}$ & 0.5 & 20 \\
\hline Aspergillus niger ${ }^{\star \star}$ & 0.5 & $>$ I00 \\
\hline Cladosporium cucumerinum ${ }^{\star \star}$ & $I^{2}$ & $>100$ \\
\hline Hansenula anomala ${ }^{\star}$ & 0.5 & $>100$ \\
\hline Saccharomyces cerevisiae ${ }^{\star \star \star}$ & 20 & $>100$ \\
\hline Bacillus subtilis" & I & IOO \\
\hline Bacterium coli ${ }^{\star}$ & $>100$ & $>$ I00 \\
\hline
\end{tabular}

* Glucose-mineral salts-agar, pH 6.5.

** Idem + biotin.

*** Malt agar, pH 6.5.

$\$$ Incubation time, 3 days.

We have no evidence at present that interference of dimethyldithiocarbamate with physiological functions of cysteine could account for its growth-inhibiting effect. At low concentrations this can at any rate not be the case because we know that copper complexes are then operative ${ }^{4}$.

The conversion of foreign $-\mathrm{SH}$ compounds into aminobutyric acid derivatives by microorganisms was also observed by us for diethyl-, dipropyl- and dibutyldithiocarbamate and for pyridine-2-thiol- $N$-oxide. We have been unable to demonstrate fungitoxic transformation products in similar experiments with monomethyldithiocarbamate and disodium ethylenebisdithiocarbamate.

The authors wish to thank Miss A. A. VAN Der Schoot and Miss G. A. M. DE GROOT for valuable technical assistance.
Institute for Organic Chemistry T.N.O., Utrecht (The Netherlands)

\author{
A. KaARs Sijpesteijn \\ J. KaSLANDER \\ G. J. M. VAN DER KERK
}

1 J. Kaslander, A. Kaars Sijpesteijn and G. J. M. Van Der Kerk, Biochim. Biophys. Acta, 52 (I96I) 396.

2 J. Kaslander, A. Kaars Sijpesteijn and G. J. M. Van Der Kerk, Biochim. Biophys. Acta, $60(1962) 4$ I 7 .

${ }^{3}$ H. M. Dekhuijzen, Nature, I9I (196I) I98.

4 A. Kaars Sijpesteijn and M. J. Janssen, Antonie van Leeuwenhoek, 25 (I959) 422.

Received April 2oth, I 962 